\title{
Immigrants in Appalachia:
}

\section{Educational Implications for Meeting the Needs of All Children}

\author{
Joy R. Cowdery \\ Muskingum University
}

U. S. A.

As rural Appalachian schools in Ohio in the United States struggle to overcome institutional bias and lack of understanding to accommodate the needs of the growing population of immigrant students from diverse countries, immigrant parents struggle to fit into a new cultural environment and to secure the best education for their children. This qualitative study of 29 southern Ohio counties examines the barriers and opportunities that each faces.

Method

Social Adjustments of Immigrant Families

School Issues

The Failure to Meet the Academic Needs of Immigrant Children

The Need for Supporting Children and Families

Conclusion

References

Nestled in the Southeastern quadrant of Ohio in the rolling foothills of the Appalachian Mountains are small cities, towns, and countrysides identified as the 29 counties of Appalachian Ohio. For the 1.48 million people who reside here (Ohio Appalachian Center for Higher Education, 2007), change has always come slowly. The majority of the population can trace their English, German, and Scot-Irish ancestry back several generations to original settlers of the first opening of the Northwest Territory. In generations past, the hills and rivers had provided protection, but also isolation for the mostly rural populations. The general population had ebbs and tides of European immigrants over the years, but most were assimilated into American culture. The face of the area remained White and English speaking.

Never a booming economic center, in former times the rivers and coal mines had at least provided a living-wage for most residents. In the past 50 years, unemployment has increased as coal mines and chemical plants shut down or moved. Now, almost $20 \%$ of the population lives in poverty (Ohio Appalachian Center for Higher Education, 2007), and an Appalachian culture continues to dominate the social climate. 
General characteristics of this culture include individualism, protestant religion, familycenteredness, love of place, humor, patriotism, and hospitality (Jones, 1994).

Educating students in rural school districts in the United States has always held economic and cultural challenges. One of those challenges is the greater distances between school districts, which may affect student access to special programs, teacher access to professional development, and administrator access to financial resources (Resources about Rural Education, 2002). Rural areas also face the combined challenges of low tax bases, isolation from job-growth centers, aging populations, and a heavy concentration of households living in or near poverty (Resources about Rural Education, 2002). Unfortunately, the 127 Southeastern Ohio schools remain the poorest in the state. The average student expenditure is $\$ 400$ less per pupil per year than the state average and continues to decrease, and teachers' salaries average $\$ 4,400$ less per year than the average teachers' salaries in Ohio (Ohio Appalachian School Districts Vital Statistic Report, 2005).

Until recently the schools had seen very little change in the faces of the students they had been serving for the last 50 years. The idea that they would need to begin to accommodate students who looked different, spoke another language, and had a different culture did not occur to most educators. While urban areas in Ohio developed English as Second Language (ESL) programs to meet the needs of a rapidly changing population, Appalachian Ohio schools were still struggling to "make do" with few resources for the dwindling population of the same students from families who had attended these schools for generations. Caught unaware in the last 10 years by a surprising number of new residents who did not speak English, Southeastern Appalachian Ohio schools are now facing not only economic barriers, but social barriers from people who are ethnocentric and culturally uninformed.

According to information based on the National Clearing House for Acquisition and Language Instruction Education Programs, Ohio saw an increase of $110 \%$ Immigrant English Language Learner (ELL) students in the last 10 years and an ELL enrollment at nearly seven times the rate of total student enrollment. According to the Ohio Department of Education in 2006, 11,356 new immigrants had enrolled in Ohio schools in less than three years for a total of over 35,000 ELL students in Ohio schools (Profile of Ohio's LEP Students, 2006). Not only is there a need to bridge language differences, but to bridge cultural differences as well. Nuclear versus extended families, an emphasis on the individual as opposed to the collective, competition versus interdependence, scientific versus intuitive ways of knowing, and verbal communication patterns rather than nonverbal patterns are often competing and contradictory cultural norms and may create distress for some students, teachers, and parents. (Kalyanpur \& Harry, 1999). Although data indicate that nearly one half $(44 \%)$ (Number of Students Served in ELL program, 2008) of the nation's ELL population lives in rural communities, a given district may have only a handful of ELL's and no teacher qualified to work with them. In rural school districts with these small numbers of ELL students, access to federal discretionary grants or other ELL-related funding that would support adequate programming is limited.

This research project was designed to examine the perceptions of schools, teachers, students, and parents in Appalachian Ohio in meeting the social and 
academic needs of ELL students through the lens of critical pedagogy (Freire,1970, Kumashiro, 2009) to understand the gaps in perception between parents and teachers and administrators of local schools that could result in inequitable treatment of these minority students. Unfortunately, many "routines" in American schools are so universally commonplace across the country that even practices that put groups of children at risk and parents at a disadvantage go unquestioned by educators (Kumashiro, 2009). As rural Appalachian schools in Ohio struggle to overcome institutional bias and lack of understanding to accommodate the needs of the growing population of immigrant students from diverse countries, immigrant parents struggle to fit into a new cultural environment and to secure the best education for their children. This qualitative study of 29 southern Ohio counties examines the barriers and opportunities that each part faces.

\section{Method}

After securing permission from the University Human Subjects Review Board, researchers on this project collected qualitative data in the Appalachian Region of Ohio from June of 2006 until December 2006. Data was collected about the demographics of recent immigrants and the impact of ELL students on rural school districts located in this area. School district administrators, teachers, and parents in Appalachian Ohio counties that had been identified by the Ohio Department of Development (2005) as being "transitional, distressed or at risk" were surveyed about their ELL populations. The surveys revealed that school administrators as a whole estimated their immigrant populations as between $0 \%$ and $5 \%$. The $5 \%$ was in a university town; however, in many instances, the researchers found teachers teaching ELL students in districts where administrators had reported having $0 \%$ immigrant students. With the exception of the district which housed a university, no policies were in place in any district to "find" ELL students or to address their needs. Census statistics from 2000 estimate a population of about $2.1 \%$ overall, but there have been dramatic increases in immigrant populations in all areas of Ohio in the last 10 years. In each county, interviews were conducted in small city districts with superintendents, principals, teachers, and if possible, parents.

A total of six superintendents, six principals, and 10 teachers were interviewed. A total of six immigrant parents from China, Mexico, Venezuela and India plus two immigrant community members from China and Mexico were interviewed three times in multiple settings. Parents and community members were interviewed by the researcher, a lifetime resident of one of the counties in Appalachian Ohio, and an undergraduate research assistant from northern Ohio as to their perceived personal success in participating in the schools and communities.

The interviews were recorded and the data analyzed with NVivo software designated for qualitative research. What emerged from the analysis was repeating topics from the community and school groups that are used as the main topics of this paper. The two subjects that dominated the parent and teacher response were their 
differing views on opportunities versus isolation and how best to meet the needs of immigrant children and their families.

\section{Social Adjustments of Immigrant Families}

The Midwest, as a whole, is seeing more immigrant growth because more immigrants are bringing families to the United States and perceive that rural communities can provide living wages and low living costs. Also, safety concerns for children are less in small towns. As one recent immigrant originally from China remarked, "The influence of violence in the little towns is minimal. We feel very secure and safe here, especially for the kids, unlike New York." Another immigrant from Mexico was insightful about his new community in his recent move and speculated on the numbers of men who do not bring their families:

This community is very welcoming. It is a good place to raise a family. Friendly, low crime, and good cost of living. It is like many of our small towns, but many of our workers do not bring their children here because they don't know if the schools can help them, and they work so much they cannot afford child care.

However, upon arriving in Appalachia, many immigrant families have discovered that the housing situation is inadequate. There are very few low-cost housing options available. Some Chinese immigrants accommodate the lack of housing in unique ways. One restaurant worker explained that instead of workers finding their own housing, the business owners are obligated to provide housing, usually in their own homes for the workers. Chinese restaurant workers in New York and Los Angeles pay a fee to agencies that then send them to work in Chinese-owned restaurants all over the United States. The owners are then obligated to house the workers as long as they remain in their particular businesses. The restaurant employee viewed the situation as "like a family, only in a restaurant." Other Mexican families share housing. Some even buy houses together. One young mother explains, "I'm a single mom with two young daughters and I work the night shift at the local Mexican restaurant. I bought a house with cash with another family who has a baby. We share expenses, and I am saving to buy my own car."

With different lifestyles and the cultural clashes with respect to expectations of school, the legal system, and community values, the families with children can experience a great deal of social stress (Hadaway, Vardell, \& Young, 2002; Taylor \& Benhke, 2005). At times, the community members' uncomfortable feelings in dealing with people from different places can take immigrants by surprise. One immigrant from New Delhi described her experience in giving birth in rural Ohio:

I had my son almost seven years ago. The nurse asked how to spell Filipino. I was confused and asked why? She was reluctant to openly discuss with me her reasons for wanting to know this. I figured she wanted to write in something for race or ethnicity in my papers and she probably felt this was an educated guess. Really, I wasn't surprised or hurt by it. I guess one gets used to these things. 
Several people have expected me to know how to read Chinese or Japanese or Korean. I always hate to disappoint them.

Some teachers expressed sympathy for new immigrant families coming into such a homogenous setting. A rural teacher who has lived in the same community for many years expressed how she believed it would be difficult for the families to become integrated given local attitudes:

I've lived in my small, little town for about twelve years and it honestly took me about ten years to actually, literally become accepted into the community myself. I know what it's like for others when they move there. Small towns are smallminded and they don't accept change very well. They think this is America, by God and if you can't speak English, get out. They have that kind of mindset and it is hard to change after a while.... Their way of thinking stays around and gets passed down onto their children and then onto their children's children and it's really sad, but that's just how it is.

Additionally, many cultural experiences that Appalachian parents and teachers assume are universal can be confusing to the new community members. A Chinese mother explains:

You have the tooth fairy and when you lose a tooth you put it under your pillow and you get a little toy or some money. Mann lost one tooth and all the people asked him what the tooth fairy brought him. Well, the parents didn't know about the thing called the tooth fairy that is supposed to come under the pillow. No one in the school tells the parents and the kids what they are supposed to do. The Easter bunny was a surprise to me. My daughter came home crying from school. 'Why did you not tell me about the Easter bunny?' All her friends brought toys and candy to school and she felt that she had been passed by because she was different. I wish the teacher had let all students know that it is OK to celebrate differently.

Cultural differences can isolate parents and in some cases even make them subject to legal action because of ignorance. Many families come from countries with few child labor laws, especially for the children who are working in a family business. As one immigrant explains:

In China, the kids help out with the family a lot because they work, ten, nine years old. But if you let people know you put your kid to work that young, they will call the child protection services on you. My friends had a 5- and 15-year-old who had to stay at the restaurant after school. They would say, 'Hey, come here and help me.' One time a customer did say something to the parents about having kids working. It is against the law, but in China, it is not."

Another area that can get immigrant parents in trouble is in disciplining their children. One immigrant parent suggested that classes for parents on laws regarding children would be helpful, "Some immigrants come from areas where domestic violence and child abuse are done. If the parents don't know that it is against the law, they will do it."

Feeling isolated can come in many forms. Because of the economic problems in Mexico, many educated and middle class workers leave to find economic security in the 
United States. Once they are here, many find they cannot step into the roles they left in their home country. The language barrier and subtle prejudice give them limited access to many middle class jobs. While manual labor may still give them more money than they had previously earned, they drop in social status. Unfortunately, many Americans view Mexican immigrants as poorly educated and incapable of academic success. One manager of a Mexican restaurant relates his experience in attending a local community college:

I am managing this Mexican restaurant here. I taught high school chemistry in Mexico. The degrees don't transfer. I decided to go back to college to retrain in business. This spring I will finish my associates' degree in business. I did take a chemistry class for fun and the teacher said, "How do you know so much?" I just laughed and said I am a chemistry teacher, too.

While all immigrants are fairly positive about their new country as a whole, they still have a desire to retain their own culture. Raising children to speak heritage language and English has its own problems. Some adult immigrants discover that their parents and children can no longer communicate. Tse (2001) labels this the "intergenerational language gap" (p.51). The parent/grandchild bond is broken. One Chinese immigrant explains the problem:

Parents try to keep children speaking Chinese. When they grow up here, they speak English and forget all of their Chinese. My mom tries to talk to my daughter, but she is too old to learn another language and she is not in a language-rich environment. My daughter cannot make herself understood in Cantonese. It is sad.

Bilingualism has benefits in that the children who are proficient in their heritage language often are better readers in English and have higher academic aspirations than their monolingual peers (Tse, 2001; Faltis \& Coulter, 2008). A Mexican father expressed his desire to keep his culture and language with the family despite the school's insistence that they speak English at home:

We are happy here, but it would be hard if we didn't speak English. My kids are very smart and I was very concerned when we moved to Ohio a year ago, and the schools didn't have any ESL to help support them to maybe catch up if they needed it. It would have been very difficult if this had been the first place in the United States that we had moved. Our children would have struggled to learn English in school and still keep up with their studies. We do speak Spanish at home all the time. We want to keep that. We want our children to continue to speak both. It would be nice to have support for that, but the schools keep telling us to only speak English at home.

A principal confirmed that was her advice to the parents of her non-English speaking students. She said, "But I know the one family; the mom speaks English well, but she will only speak Spanish at home. So I talked to her about the importance of their heritage, but if they want their son to stay here, he will have to know English. They need to speak English." Research supports the need for immigrant families to retain their heritage language to increase success in academic English language and support improved self-esteem (Bermudez, 1994). 
Other immigrants are very determined to learn English and about American culture quickly. Lacking resources in the community, one ingenious immigrant turned to television as the teacher:

It's hard to have to put the words together to make a sentence. It took me about three months. I stayed home and watched TV. And the one TV show that helped me a lot was the Family Feud. Because of the surveys...the American way of things... like the top five this or that. It was a way to adjust to the American way of thinking.

\section{School Issues}

Perhaps the most difficult and frustrating cultural clashes for parents come because of the lack of help they can give their children in school and the lack of resources schools have to help them. For most couples with young children, making a living takes a priority, but they are very concerned with their children's education. Homework poses more-than-logistic problems. As one young immigrant father who owns his own restaurant explained through a translator:

Homework from the beginning has been trouble because we don't speak English. If the homework said to have parents read to the child, that is a big problem. Sometimes our son who is only six gets very upset with us. We cannot help him with his English studies. For math, we can do it, we understand two plus two equals four when it is written down in numbers, but we cannot use the language that his teachers use. He says, 'Why can't you tell me?' I think he thinks we are stupid.

Because most teachers and administrators in Southeastern Ohio have no specific training in working with English language learners, subtle biases based on media-fueled stereotypes can surface, which may influence their dealings with a child. While teachers almost always want to help children, because of a lack of training or experience with other cultures many may reveal a negative perception to the child or family.

One teacher, in her description of her experience with her first non-English speaking child, revealed some bias that teachers may not realize they have in dealing with a child:

This child came with her mother and dad...well, I assume that he's "Dad" but maybe he's her boyfriend. I'm not quite exactly sure. Anyway, the first day of school, I got a call down to the office and there was she was sitting in the chair with her mother. Mom knew barely any English and she knew even less. I was lucky that she learned quickly. I can see where we could have had bigger problems.

Just using the word "problems" to predict outcome indicates a negative expectation of the experience. This teacher would not view her judgment of the family as ethnocentric because to her it was just "common sense" that "these people" were probably morally 
inferior and that not speaking English was a "problem." Another teacher described where a student came from in rather dismissive terms: "We had some kids a few years ago from, I can't remember the country, I think it was a Soviet Union country and they divided up into one of those countries that has about twelve names and about twelve letters in the name." Clearly the child's country and culture was of no interest to the teacher. Another elementary teacher who volunteered to take her Chinese student to an after-school activity expressed surprise at learning that the child had no Christian background knowledge:

We'd be driving in the car. I mean I remember one time taking him down the alley in the car going home past the Catholic church and he had no idea what that was. "What is that?" That's a church. Well, "What was God...?" Well I mean that whole thing was like wow, mmhmm...

One teacher, clearly offended by the cultural custom of the parent, described a parentteacher conference with a Hindu parent in the following words, "She came dressed in her clothes from her country and that thing on her forehead and she spoke very broken English."

These teachers would never classify themselves as having a bias because the bias is so engrained in the American experience that they would not recognize it as such (Kumashiro, 2009). If asked, these teachers would say they were very open and understanding, but subtle institutionalized prejudices colored the way they viewed students. Expectations of students may predict outcomes, and subconsciously labeling children negatively may hinder their learning (Merton, 1938, Rosenthal \& Jacobson, 1968). Lack of exposure to other cultures and lack of education in diverse cultures leaves many teachers unaware of how their perceptions of the "other" may be hurtful to a child (Gibson, et al., 2004).

Teachers and principals also have adjustments to make in dealing with immigrant families. Issues that they have never dealt with before must be addressed. One principal explained the difficulty of working with immigrants who both came from a warring African nation (note the use of the term "tribe" which implies a more primitive group to describe the children's background):

It seems that the different tribes were at war at home. One family sent a note to a teacher saying their child was not allowed to sit near or associate with another child from another tribe. The school set up a meeting with both parents and refused to comply with the request stressing that while in United States all cultures must be respected and all people must work together. It took some time, but eventually the two young men learned to work with one another or avoid one another. It must be similar to how urban schools must have to deal with gangs.

Not only are subtle biases a problem in working with immigrant children, but a lack of education in how to structure a program to meet the diverse needs of a diverse population may interfere with the educational process. Because of the few numbers of immigrants in each of the districts and the geographically challenging connection to other districts, most Appalachian school districts are at a disadvantage in providing support for immigrant students and their families. Schools are a central social institution 
for most of the small communities and these families are often isolated by those very institutions.

\section{The Failure to Meet the Academic Needs of Immigrant Children}

The laws regarding immigrant, non-English speaking students are clear and have been around for quite some time. In 1974, the Supreme Court found in Lau v. Nichols that all schools must have a plan for educating English Language Learners. More recently, Title III and NCLB have specified procedures and assistance for school districts to help all students meet the challenging state standards required by No Child Left Behind (No Child Left Behind Act of 2001).

According to the Lau Resource Center for English as a Second Language (ESL), Bilingual, and Multicultural Education, part of the Ohio Department of Education Center for Families and Communities Office for Exceptional Children, schools are obligated to assess the language needs of all students in a systematic way and to then provide services to students who need ESL instruction. While there are no legitimate excuses, in Appalachian Ohio most administrators and teachers are neither aware of the required procedures nor of the help and support available. Even the process of enrolling immigrant students may be daunting to parents in rural areas. One principal reported that several Mexican immigrant parents never came back when they were asked to produce proof of citizenship. He was completely unaware that he was not legally allowed to require proof. Most administrators report that they do the "best they can" to work with their children but are at a loss as to what needs to be done to ensure an appropriate education for non-English speaking students.

The following are accounts of how these schools have tried to work with children with little information, training, or support:

Our teachers didn't know what to do, so luckily we had a paraprofessional who was Chinese and she worked with the child. But if we hadn't had the aide, I'm not sure (Assistant Superintendent).

We have random Chinese students in our high school when their parents come in to work at the Chinese restaurant. We also occasionally have young Mexican students in the elementary schools. Our librarian works individually with the five high school students we have, but she has no training. She just has time and interest (High School Principal).

I teach high school Spanish and I was the one who was expected to work with and communicate with Spanish-speaking students and I was overwhelmed. We don't have anyone hired to teach ELL because of the fact that ESL students are so far and few between, but at the same time, I was expected to do it myself on top of my high school Spanish classes (High School Spanish Teacher).

And when he [student] came to our school, he was in third grade. He virtually spoke no English, and yet he was expected to take the third grade proficiency test. And he was given a dictionary. That was the only accommodation he was 
allowed to have. He struggled, socially and academically even though I knew he was very bright...so that was pretty criminal (Third Grade Teacher).

Most teachers were concerned with their lack of knowledge in teaching these children. They recognized that they needed professional development to better serve these students. Two fifth-grade teachers expressed that they were "flying by the seats of our pants" in teaching English Language Learners. The lack of financial and professional development support is evident.

The school administrators seemed to be more concerned with another issue. While the majority of the responding school district administrators realized that the population of English Language Learners was growing in their area, only a few described this as priority for their districts. Specifically, the majority of administrators responded that their primary concern was only that ELL achievement test scores were counted in the school's report card. A majority also admitted that their ELL students did not do as well academically as their English-speaking students. Other studies have confirmed that many administrators view the ELL population as outsiders who negatively affect the overall academic outcomes of their schools (Florez-Gonzalez, 2002; Gibson \& Koyama, 2004.)

\section{The Need for Supporting Children and Families}

One of the functions of schools is not only to support their students, but to reach out to the community and support families. Much research has pointed the importance of supporting families to enhance the lives and academic success of children (Boyson \& Short, 2003; Henderson \& Berla, 1994; Epstein, 1995; Walker \& Sprague, 1999,). Schools have traditionally filled this role for rural communities (Bauch, 2001). It only seems natural that they should be helping to fill the social support void for their immigrant families.

The need for support is echoed by the participants in this study. Parents reported feeling that education was very important for their children. They were all concerned with their child's academic success but felt helpless in assisting their child with school work and isolated from their children's schooling. Schools have historically bridged the family/school gap in ways unique to their own communities. Having a variety of afterschool options and advocating for low cost child-care could accommodate some of these families', as well as other families', needs. Classes or social events that taught both American and Appalachian culture were suggested by one immigrant parent. Immigrant families want to be a part of their new home, and schools could provide a way to begin to integrate them into the community while still retaining aspects of their native culture.

One of the main obstacles, which remains in supporting these immigrants in Appalachia, is an attitudinal barrier. As one native resident expressed it, "Appalachians as a community are slow to change. I would have to say that our community is afraid of change and is afraid of immigrants moving in and because of that, they (immigrants) 
aren't embraced." A principal recognized the same resistance as his students grew older:

With the younger kids, I think that Spanish-speaking kids get embraced quicker because everyone sees them as something new and exciting, so they are cool and everyone gets along with them. But as they get older, it starts to change because kids are getting preconceived notions that their parents have or that they pick up from people and it makes it hard for students to get involved and feel a part of the group.

Schools could become the catalyst for changing some of the negative views (Catalano, 2006). They could become the advocates for supporting families within a community. One teacher assessed the situation with the following comment, "The community needs educated as well as the immigrant children. They need to know that people are different and that is OK."

\section{Conclusion}

The results of this research show that while immigrant and English Language Learners in rural Southeastern Ohio are still few in numbers and isolated across several districts, it is a population that is steadily growing and inadequately supported in schools and communities. As these new members of small communities become part of the social and financial networks of the region, efforts are needed to make their adjustment to the culture of both the United States and Appalachia easier and more productive. With the geographic and physical restraints of rural school districts, meeting the needs of all students becomes a task that requires creative and innovative solutions. By requesting local colleges to offer courses in TESOL (Teaching English to Speakers of Other Languages) and cultural sensitivity school districts could provide training for administrators and teachers. This training can also be done with technology from larger, but more distant, universities. Schools must also be more proactive in thinking globally in providing extracurricular activities and after-school programs. Opportunities for the traditional community to socialize and work with new immigrant families will lead to reducing fear and bias for many people. Finally, schools can partner with community organizations to provide English language instruction for parents and adult learners.

Deep-seated prejudice of "outsiders" does not disappear without intervention. Just as rural public schools have brought people from a wide geographic area of different races, classes, and religions together as a sub-community that feels unified through academic, athletic, and extra-curricular activities, so can they bridge this gap in language and cultural differences. It will take time and "willingness" on the part of the teachers and administrators to accomplish this. The "willingness" can only come with better education and professional development of those educators.

Immigrant families come to the United States for many reasons: some come for improved economic opportunities, some to join family members, and some to escape political or religious prosecution. Most come with very positive expectations of having a

better life. Appalachian Ohio is a chance at a better life for most immigrants. The 
communities are safe, and the cost of living is low. These immigrants want what all children want: a secure family and community, friends, and a good education to lead them to these opportunities. Failing to meet the needs of just one child and his or her family is failing to help a member of our community become a productive, satisfied citizen and to ensure equitable treatment of all students.

\section{References}

Bauch, P. A. (2001). School-community partnerships in rural schools: Leadership, renewal, and a sense of place. Peabody Journal of Education, 76(2), 204-221.

Bermudez, A. B. (1994). Doing our homework. How schools can engage Hispanic communities: Culturally and linguistically appropriate services. Early Childhood Reserch Insititute. Retrieved October 6, 2006 from http://clas.uiuc.edu/fulltext.c100136/chpt.html

Boyson, B., \& Short, D. (2003). Secondary school newcomer programs in the United States. Santa Cruz, CA: Center for the Research on Education, Diversity and Excellence.

Catalano, P. (2006). Reaching out to immigrant parents. Retrieved October 23, 2009 from http://ptodtoday.com/0805immigrantparents.html

Epstein, J. L. (1995). School/family/community partnerships: Caring for the children we share. Phi Delta Kappan, 76(9), 701-712.

Faltis, J. F., \& Coulter, C. (2008). Teaching English language learners and immigrant students in secondary schools. Upper Saddle River, NJ: Pearson.

Flores-Gonzalez, N. (2002). School kids/street kids: Identity development in Latino students. New York: Teachers College Press.

Freire, Paulo. (1970). Pedagogy of the oppressed. New York: Continuum.

Gibson, M., Gandrar, P., \& Koyaman, J. P. (Eds.). (2004). School connections: U.S. Mexican youth, peers, and school achievement. New York: Teachers College Press.

Hadaway, N. L., Vardell, S. M., \& Young, T. (2002). Literature-based instruction for English language learners: K-12. Boston: Allyn \& Bacon Longman.

Henderson, A., \& Berla, N. (1994). A new generation of evidence: The family is critical to student achievement. Washington, D.C.: National Committee for Citizens in Education, Center for Law and Education.

Jones, L. (1994). Appalachian values. Ashland, KY: The Jesse Stuart Foundation.

Kalyanpur, M., \& Harry, B. (1999). Culture In special education: Building reciprocal family - professional relationships, Baltimore: Brookes Publishing Company.

Kumashiro, K. (2009). Against common sense: Teaching and learning toward social justice. New York: Routledge. 
Merton, R. K. (1938). Social structure and anomie, American Sociological Review, 3(5), $672-82$.

No Child Left Behind Act of 2001, Title III, Part C , Sec. 3302. Statutory Requirements and Parent Notification. Office of English Language Acquisition, Language Achievement for Limited English Proficient Students (OELA). Title III State Directors Meeting. Thursday, Nov. 14, 2002. The Hilton Washington Hotel, Washington D.C.

Number of Students Served in ELL Program (2003). Retrieved October 23, 2009 from http://nces.ed.gov/Pubs2003/100 largest/tables/table 20 1.asp - 40k

Ohio Appalachian School Districts Vital Statistics Report (2005). Fiscal year 2005. Compiled by the Coalition of Rural and Appalachian Schools. Ohio University, Athens, Ohio, May 2006.

Ohio Appalachian Center for Higher Education. About Appalachians. Retrieved August 29, 2007 from http://www.oache.org/app.facts.html

Profile of Ohio's LEP Students. Lau Resource Center (2006). Retrieved July 7, 2006 from communities/Lau Resource Center/

Resources about Rural Education. National Clearinghouse for English Language Acquisition and Language Instruction Educational Programs. (2002) Washington, D.C., Retrieved January $\quad 1, \quad 2007$

from http://www.ncela.gwu.edu/resabout/rural/index.html

Rosenthal, R., \& Jacobson, L. (1968). Pygmalion in the classroom. New York: Holt, Rinehart and Wilson.

Taylor, B., \& Behnke, A. (2005). Fathering across the border: Latino fathers in Mexico and the U.S. Fathering, 3(2), 99-120.

Tse, L. (2001). Why don't they learn English: Separating fact from fallacy in the U.S. language debate. New York: Teachers College Press.

Walker, H. M., \& Sprague, J. R. (1999). The path to school failure, delinquency and violence: Causal factors and some potential solutions. Intervention in School and Clinic, 35(2), 67-73. 